\title{
Determination of Static Recrystallization Critical Temperature of Austenite in Microalloyed Steels
}

\author{
S. F. MEDINA and J. E. MANCILLA ${ }^{1)}$
}

Centro Nacional de Investigaciones Metalúrgicas (CENIM-CSIC), AV. Gregorio del Amo 8, 28040-Madrid, Spain. 1) Universidad Autonoma de Puebla, UAP, Rio Sabinas 6109, 72570-Puebla, Mexico.

(Received on June 29, 1993; accepted in final form on September 24, 1993)

\begin{abstract}
A method is developed which makes it possible to determine with precision the static recrystallization critical temperature (SRCT) of austenite in microalloyed steels, in other words the temperature at which recrystallization starts to be inhibited. Using torsional tests and applying the back extrapolation method the recrystallized fraction of the austenite has been determined at two strains $(0.20$ and 0.35$)$ and several temperatures in three steels with $\mathrm{Nb}, \mathrm{V}$ and $\mathrm{Ti}$ respectively. The graphic representation of the activation energy $v s$. the inverse of the temperature makes it possible to determine the SRCT of each steel as a function of the strain and the austenite grain size. The comparison of the SRCT with the solubility temperature calculated for nitrides and carbides indicates the nature of the precipitates. With the results obtained a model had been constructed for the recrystallized fraction both at temperatures above and below SRCT, and this, together with other equations already published, calculates the residual strain and the austenite grain size which the steel will have at the end of rolling and before the $\gamma \rightarrow \alpha$ transformation. The graphs of the recrystallized fraction $v s$. time show the kinetics of the induced precipitation and the PTT diagrams (precipitation-time-temperature) have been determined for the three steels.
\end{abstract}

KEY WORDS: static recrystallization; activation energy; recrystallization critical temperature; induced precipitation kinetics.

\section{Introduction}

It is known that the kinetics of the static recrystallization of austenite can be described by an equation of Avrami in the following way:

$$
X_{a}=1-\exp \left[-0.693\left(\frac{t}{t_{0.5}}\right)^{n}\right]
$$

where $X_{a}$ is the fraction of the recrystallized volume and $t_{0.5}$ is the time corresponding to half of the recrystallized volume, which depends practically on all the variables which intervene in the hot deformation and whose most general expression follows a law of the type:

$$
t_{0.5}=A \varepsilon^{p} \dot{\varepsilon}^{q} D^{s} \exp \frac{Q}{R T}
$$

where $\varepsilon$ is the strain, $\dot{\varepsilon}$ the strain rate, $D$ the grain size and $Q$ the activation energy. Recently it has been demonstrated that the activation energy is the parameter which is most sensitive to the changes of composition and which can be expressed as a function of the content of each alloy forming element. ${ }^{1)}$ On the other hand, for most authors the exponent $n$ in Eq. (1) is a constant and for others ${ }^{2)}$ follows a similar law to Eq. (2).

The strain induced precipitation inhibits static recrystallization and if the deformation is carried out at temperatures lower than that at which this inhibition commences, a temperature which we shall henceforth refer to as the static recrystallization critical temperature (SRCT), the recrystallization kinetics are different, it being necessary to modify Eq. (2) as the activation energy stops being a constant and comes to be a function of the temperature. $^{1,3)}$ Most of the models for static recrystallization $^{4-10)}$ do not make provision for this and are applied to $\mathrm{C}-\mathrm{Mn}$ steels and to a lesser extent to microalloyed steels, and in the latter case only in the range of temperatures where the microalloy is in solution or where precipitation has still not been sufficient to inhibit recrystallization. Some authors ${ }^{5,12-14)}$ establish for the microalloyed steels with $\mathrm{Nb}$ that when the strain temperature is lower than the solubility temperature of the precipitates (nitrocarbides of $\mathrm{Nb}$ ) recrystallization is more difficult and the activation energy increases slightly.

Knowing the SRCT of microalloyed steels is of great importance in hot rolling, ${ }^{3,15-18)}$ as a rolling whose final passes take place at temperatures lower than SRCT will give reise to an accumulated strain of the austenite (pancaking). The consequence of this will be that the ferrite grain which is obtained after the $\gamma \rightarrow \alpha$ transformation will be much smaller than if the successive passes were carried out at temperatures above SRCT.

Dutta and Sellars ${ }^{19)}$ defined "the recrystallization stop temperature (RST)" related with the precipitation and determined when the time corresponding to $5 \%$ of the 
recrystallized fraction $\left(t_{0.05 x}\right)$ is equal to $5 \%$ of the induced precipitation $\left(t_{0.05}\right)$ using two mathematical expressions, the first deduced experimentally and the second semi-theoretically based on the theory of diffusion-controlled nucleation. ${ }^{20)}$ Likewise, they also defined the "recrystallization limit temperature (RLT)" as the lowest temperature at which roughing reductions should be given if mixed microstructures arising from partial recrystallization are to be avoided in commercial rolling, taking $85 \%$ as the total recrystallization criterion. The authors recognize that up to the time when Ref. 5) was published (1987) the effect of strain, or rolling reduction, in the first finishing pass on the RST does not appear to have been studied experimentally.

The work of Dogan et al., ${ }^{21}$ ) is one of the first in which the no-recrystallization temperature $\left(T_{n r}\right)$ is determined experimentally, coinciding with Dutta's RLT, for a steel with $\mathrm{Ti}-\mathrm{V}-\mathrm{N}$ and established the different microstructures which are obtained when the steel is rolled below or above the $T_{n r}$. A method determining the $T_{n r}$ has been developed by Jonas et al. ${ }^{16-18,22,23)}$ It consists of the simulation of a schedule consisting of 17 passes each of 0.2 equivalent strain, with $30 \mathrm{~s}$ interpass delays at a strain rate of $2 \mathrm{~s}^{-1}$ and a cooling rate of $1^{\circ} \mathrm{C} / \mathrm{s}$. The $T_{n r}$ can be determined from the variation of the mean flow stress (MFS) for each pass, calculated by numerical integration, with absolute inverse pass temperature. It is necessary to indicate that $\mathrm{Cudy}^{24)}$ experimentally determined RST as a function of the content of the microalloying. The temperature defined above as SRCT is approximately the same as $T_{n}$ and RLT as the three refer to the start of the inhibition of recrystallization, through the methods for their determination are different.

In this work the static recrystallization kinetics of three micralloyed steels with $\mathrm{Nb}, \mathrm{V}$ and $\mathrm{Ti}$ respectively are studied using torsional tests. SRCT is determined for each one of them as a function of the strain and the austenite grain size and Avrami's equation is expressed both in the range of temperatures above SRCT and the range of temperatures between SRCT and the temperature of the $\gamma \rightarrow \alpha$ transformation $\left(\mathrm{A}_{\mathrm{r} 3}\right)$. These equations, together with others already published, ${ }^{3)}$ make it possible to calculate the residual strain and the austenite grain size at the end of any hot rolling schedule.

The determination of the recrystallized fraction was carried out using the method known as back extrapolation, ${ }^{25)}$ as with this method the softened fraction is approximately equal to the recrystallized fraction. ${ }^{26)}$ In this way, as we shall see later, it has also been possible to estimate the precipitation kinetics (PTT diagrams), observing the changes of slope in the curves which show the recrystallized fraction $v s$. time.

\section{Experimental Procedure}

The steels used were manufactured by electroslag remelting (ESR), in a unit capable of producing $30 \mathrm{~kg}$ ingots. This technique avoids macrosegregation, both in alloying elements and impurities, and there is considerably less microsegregation, these defects being present in conventional ingots and continuous casting
Table 1. Chemical composition of the steels. (wt \%)

\begin{tabular}{c|ccccccc}
\hline Steel & $\mathrm{C}$ & $\mathrm{Si}$ & $\mathrm{Mn}$ & $\mathrm{Nb}$ & $\mathrm{V}$ & $\mathrm{Ti}$ & $\begin{array}{c}\mathrm{N} \\
(\mathrm{ppm})\end{array}$ \\
\hline $\mathrm{Nb}$ & 0.105 & 0.240 & 1.230 & 0.042 & - & - & 112 \\
$\mathrm{~V}$ & 0.113 & 0.226 & 1.030 & - & 0.095 & - & 144 \\
$\mathrm{Ti}$ & 0.145 & 0.260 & 1.100 & - & - & 0.075 & 102 \\
\hline
\end{tabular}

Table 2. Austenite grain size $(D)$ at $1230^{\circ} \mathrm{C} \times 10 \mathrm{~min}$ and critical temperature $\mathrm{A}_{\mathrm{r} 3}$ for different cooling rates.

\begin{tabular}{c|cccc}
\hline Steel & $D(\mu \mathrm{m})$ & $\begin{array}{c}\mathrm{A}_{\mathrm{r} 3}\left({ }^{\circ} \mathrm{C}\right) \\
\left(0.2^{\circ} \mathrm{C} / \mathrm{s}\right)\end{array}$ & $\begin{array}{c}\mathrm{A}_{\mathrm{r} 3}\left({ }^{\circ} \mathrm{C}\right) \\
\left(1^{\circ} \mathrm{C} / \mathrm{s}\right)\end{array}$ & $\begin{array}{c}\mathrm{A}_{\mathrm{r} 3}\left({ }^{\circ} \mathrm{C}\right) \\
\left(5^{\circ} \mathrm{C} / \mathrm{s}\right)\end{array}$ \\
\hline $\mathrm{Nb}$ & 122 & 786 & 745 & 693 \\
$\mathrm{~V}$ & 165 & 784 & 753 & 731 \\
$\mathrm{Ti}$ & $125^{*}$ & 776 & 731 & 676 \\
\hline
\end{tabular}

* heating $1100^{\circ} \mathrm{C} \times 10 \mathrm{~min}$.

billets. In this way, the results of the specimens offer greater guarantees of accuracy.

The compositions of the three steels studied are shown in Table 1. Torsional tests were carried out on a machine that enabled automatic programming of each test in terms of applied strain, strain rate, temperature, etc. ${ }^{27)}$ The specimens used had a useful length of $50 \mathrm{~mm}$ and a diameter of $3 \mathrm{~mm}$ and were heated by induction, protected by a current of argon, and the temperature was monitored by a previously calibrated optical pyrometer. The heating temperature was $1230^{\circ} \mathrm{C} \times$ $10 \mathrm{~min}$, obtaining a complete dissolution of the precipitates, except the titanium nitrides which, as is known, only become completely dissolved at much higher temperatures. Subsequently the temperature was reduced to the testing temperature in a time of less than two minutes, sufficient time to avoid precipitation and to establish the testing temperature. Stress-strain curves were obtained from torque-No. of turns by using wellknown equivalence equations. ${ }^{28)}$ The recrystallized fraction was determined at different temperatures, at the equivalent strains of 0.29 and 0.35 , and the strain rate was always $3.63 \mathrm{~s}^{-1}(=1000 \mathrm{rev} / \mathrm{min})$. The strain of 0.35 in no case exceeded the strain necessary for dynamic recrystallization to commence in any of the steels. Other tests at a heating temperature of $1100^{\circ} \mathrm{C} \times 10 \mathrm{~min}$ were carried out with the aim of finding the influence of the grain size on SRCT.

\section{Results and Discussion}

First, the austenite grain size of steels was measured at the austenization temperature $\left(1230^{\circ} \mathrm{C} \times 10 \mathrm{~min}\right)$ which was calculated as the mean of the values obtained by linear intersection in the observation of twenty fields of the quenched microstructure (Table 2).

To ensure that the testing temperatures corresponded to the austenitic phase, the critical transformation temperatures were measured by dilatometry. The values at different cooling rates are also shown in Table 2 . As was to be expected the steel with Ti shows the smallest 


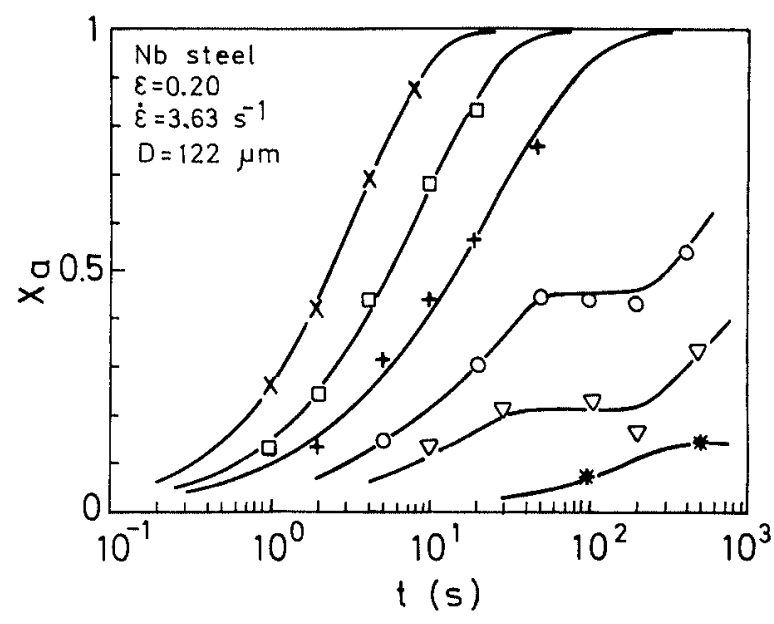

Fig. 1. Variation of the recrystallized fraction $\left(X_{a}\right)$ with time for $\mathrm{Nb}$ steel. $\varepsilon=0.20 ; \quad \dot{\varepsilon}=3.63 \mathrm{~s}^{-1} ; \quad x=1150^{\circ} \mathrm{C}$; $\square=1100^{\circ} \mathrm{C} ;+=1050^{\circ} \mathrm{C} ; O=1000^{\circ} \mathrm{C} ; \nabla=975^{\circ} \mathrm{C}$; $*=950^{\circ} \mathrm{C}$.

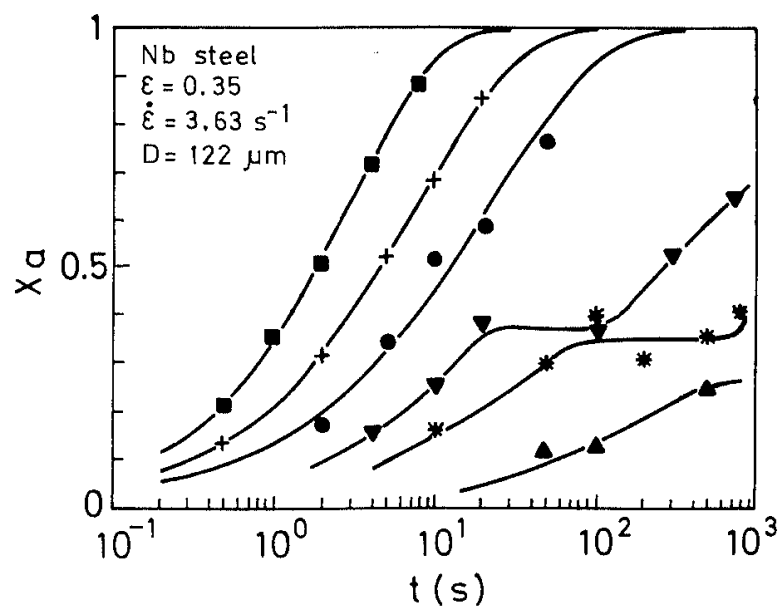

Fig. 2. Variation of the recrystallized fraction with time for $\mathrm{Nb}$ steel. $\varepsilon=0.35 ; \quad \dot{\varepsilon}=3.63 \mathrm{~s}^{-1} ; \quad \boldsymbol{\square}=1100^{\circ} \mathrm{C} ;+=$ $1050^{\circ} \mathrm{C} ; \boldsymbol{\theta}=1000^{\circ} \mathrm{C} ; \boldsymbol{\nabla}=975^{\circ} \mathrm{C} ; *=950^{\circ} \mathrm{C} ; \boldsymbol{\Delta}=$ $900^{\circ} \mathrm{C}$.

grain size, as it is known that $\mathrm{Ti}$ is a good refiner of the austenite grain. Furthermore, the greater carbon content of this steel gives a lower temperature $A_{r 3}$ than the other two steels, whatever the cooling rate. On the other hand the greater manganese content of the steel with $\mathrm{Nb}$, compared with the steel with $\mathrm{V}$, also produces a slight reduction in the temperature $A_{r 3}$.

The recrystallized fraction for each temperature and strain was measured as a function of time, and where total recrystallization occurred the resultant curves were plotted by regression with Eq. (1). Figure 1 shows the recrystallized fraction of steel with $\mathrm{Nb}$ for a strain of 0.20 and at different temperatures. The curves corresponding to 1150,1100 and $1050^{\circ} \mathrm{C}$ show the classic kinetics of static recrystallization, in accordance with Eqs. (1) and (2), but the $1000^{\circ} \mathrm{C}$ curve and curves for other lower temperatures show a plateau whose amplitude varies according to the temperature, being greater as the temperature descends. Figure 2 shows the recrystallized fraction for the same steel at a strain of 0.35 , it being observed that now the plateau begins to oc-

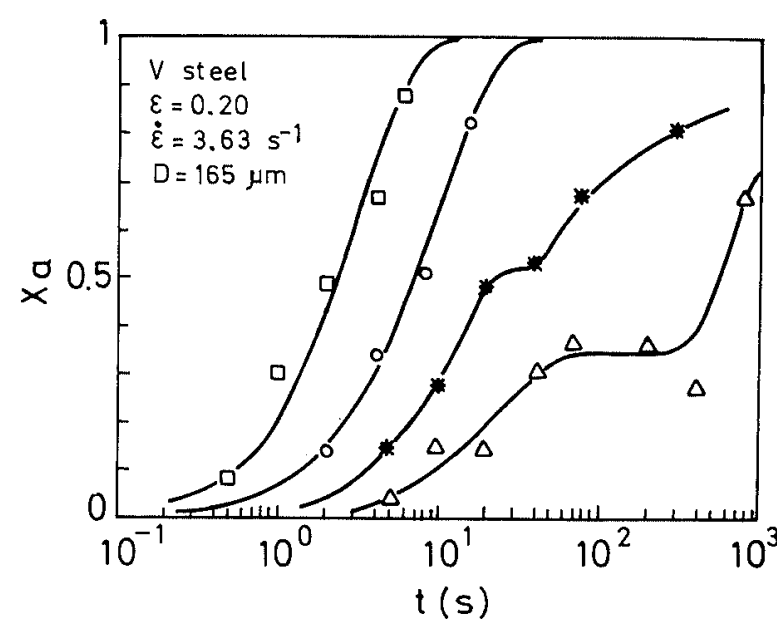

Fig. 3. Variation of the recrystallized fraction with time for $V$ steel. $\varepsilon=0.20 ; \dot{\varepsilon}=3.63 \mathrm{~s}^{-1} ; \quad \square=1100^{\circ} \mathrm{C} ; \quad O=$ $1000^{\circ} \mathrm{C} ; *=950^{\circ} \mathrm{C} ; \triangle=900^{\circ} \mathrm{C}$.

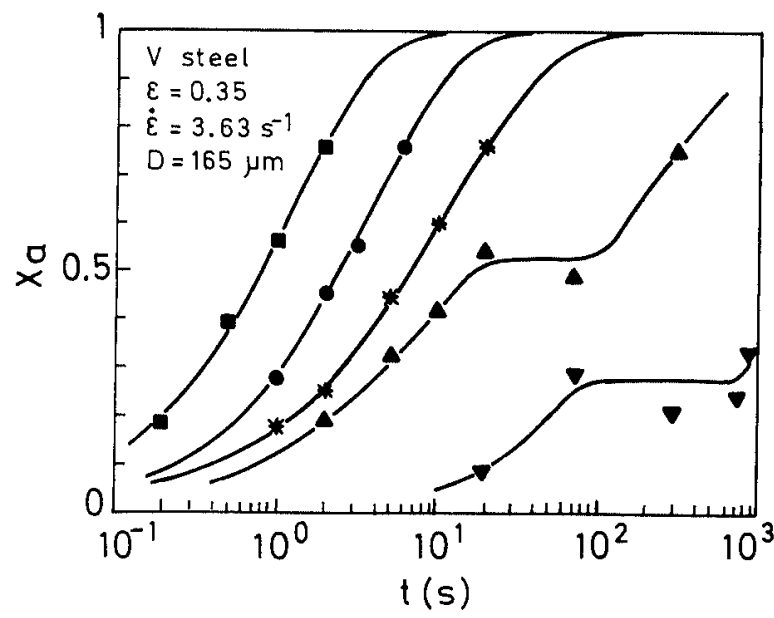

Fig. 4. Variation of the recrystallized fraction with time for $\mathrm{V}$ steel. $\varepsilon=0.35 ; \quad \dot{\varepsilon}=3.63 \mathrm{~s}^{-1} ; \quad \mathbf{\quad}=1100^{\circ} \mathrm{C} ; \quad \mathbf{\theta}=$ $1000^{\circ} \mathrm{C} ; *=950^{\circ} \mathrm{C} ; \boldsymbol{\Delta}=900^{\circ} \mathrm{C} ; \boldsymbol{\nabla}=850^{\circ} \mathrm{C}$.

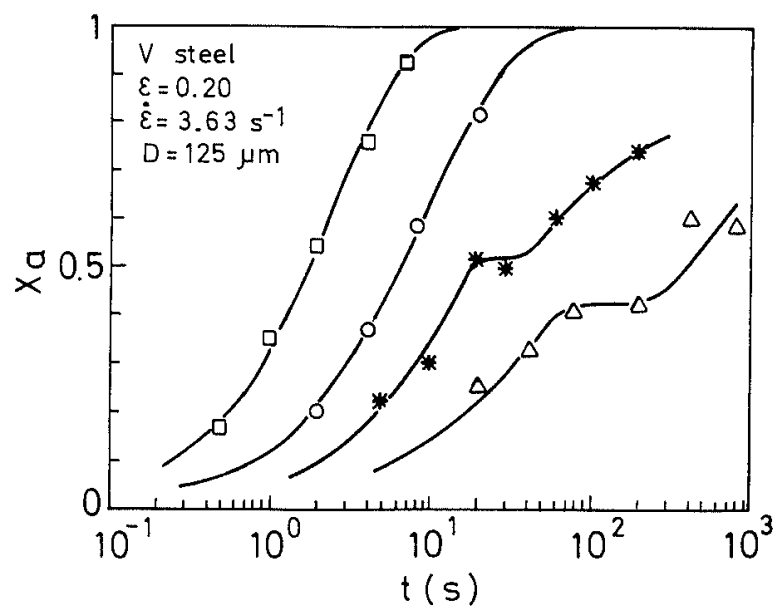

Fig. 5. Variation of the recrystallized fraction with time for $V$ steel. $D=125 \mu \mathrm{m} ; \varepsilon=0.20 ; \dot{\varepsilon}=3.63 \mathrm{~s}^{-1} ; \square=1100^{\circ} \mathrm{C}$; $\mathrm{O}=1000^{\circ} \mathrm{C} ; *=950^{\circ} \mathrm{C} ; \triangle=900^{\circ} \mathrm{C}$.

cur at temperatures lower than $1000^{\circ} \mathrm{C}$.

Figures 3 and 4, corresponding to the steel with $\mathrm{V}$ and strains of 0.20 and 0.35 respectively, show similar results, although in this case the temperature at which the plateau 


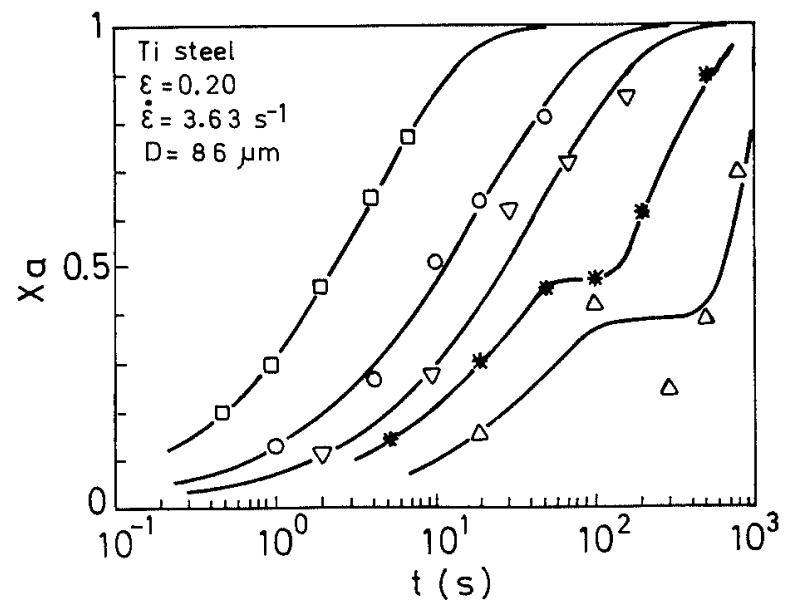

Fig. 6. Variation of the recrystallized fraction with time for Ti steel. $\varepsilon=0.20 ; \quad \dot{\varepsilon}=3.63 \mathrm{~s}^{-1} ; \quad \square=1100^{\circ} \mathrm{C} ; \quad O=$ $1000^{\circ} \mathrm{C} ; \nabla=950^{\circ} \mathrm{C} ; *=925^{\circ} \mathrm{C} ; \triangle=900^{\circ} \mathrm{C}$

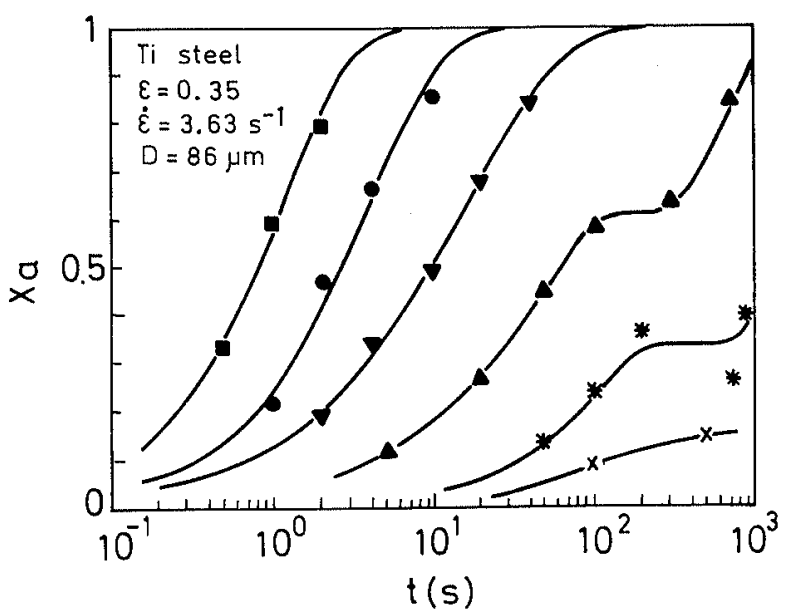

Fig. 7. Variation of the recrystallized fraction with time for Ti steel. $\quad \varepsilon=0.35 ; \quad \dot{\varepsilon}=3.63 \mathrm{~s}^{-1} ; \quad \mathbf{v}=1100^{\circ} \mathrm{C} ; \quad \boldsymbol{\theta}=$ $1000^{\circ} \mathrm{C} ; \quad \boldsymbol{\nabla}=950^{\circ} \mathrm{C} ; \quad \boldsymbol{\Delta}=900^{\circ} \mathrm{C} ; \quad *=875^{\circ} \mathrm{C} ; \quad x=$ $850^{\circ} \mathrm{C}$.

begins to appear differs from the previous examples due to the different nature of the precipitates.

Figure 5 shows the recrystallized fraction also for the steel with $\mathrm{V}$ at a strain of 0.20 , but with an austenite grain size of $125 \mu \mathrm{m}$ obtained with heating to $1100^{\circ} \mathrm{C} \times 10 \mathrm{~min}$. Though it may have been more desirable to obtain a smaller grain size in comparison with the grain size of $165 \mu \mathrm{m}$ obtained with heating to $1230^{\circ} \mathrm{C} \times 10 \mathrm{~min}$, the aim was to start with an austenite in which all the precipitates were dissolved and in this way to be able to study the influence of the grain size both on the recrystallized fraction and on the kinetics of the induced precipitation.

In the same way, the steel with $\mathrm{Ti}$ offers the curves shown in Figs. 6 and 7, corresponding to the two strains mentioned, and as in the previous cases it also presents the plateau when the temperature is equal to or lower than $925^{\circ} \mathrm{C}$ for the strain of 0.20 , and equal to or lower than $900^{\circ} \mathrm{C}$ for the strain of 0.35 .

The presence of the plateau indicates that induced precipitation has taken place, and this brings about a considerable delay in the recrystallization kinetics. The

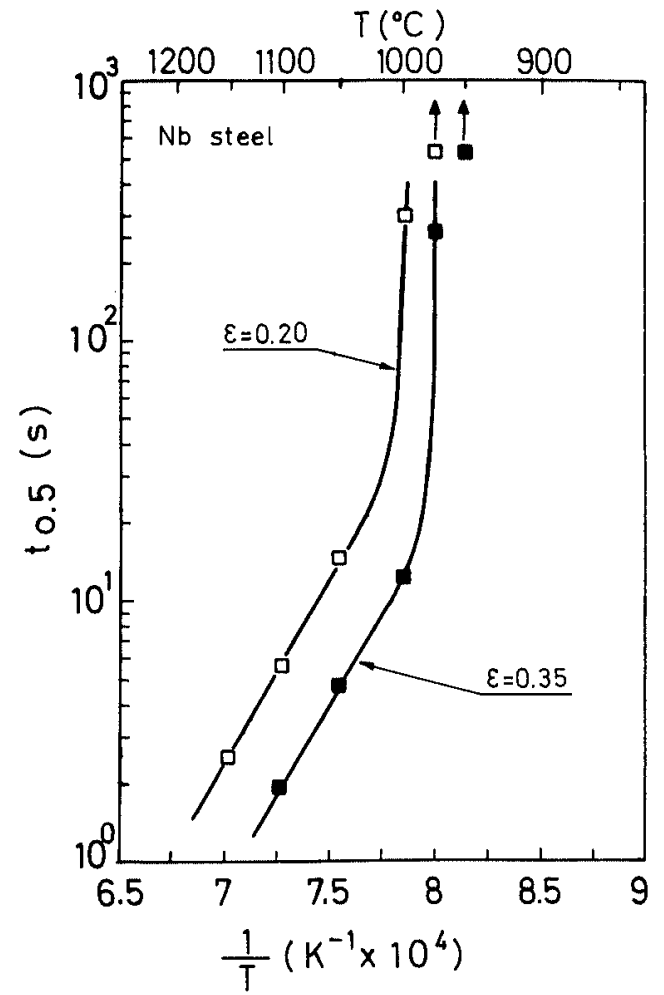

Fig. 8. Plot of $t_{0.5}$ against the reciprocal of the temperature for $\mathrm{Nb}$ steel.

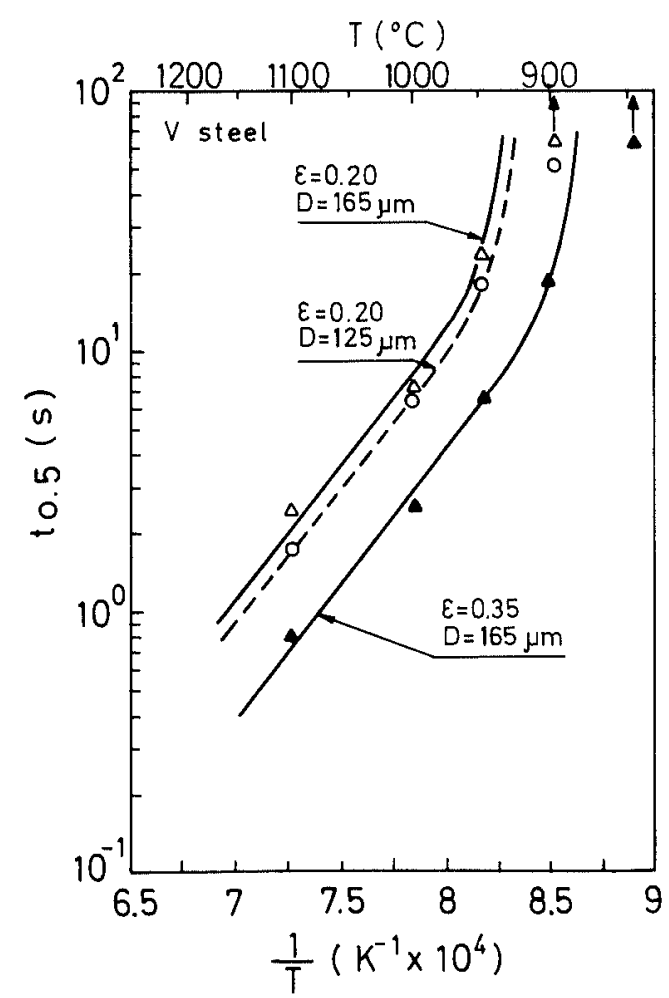

Fig. 9. Plot of $t_{0.5}$ against the reciprocal of the temperature for V steel.

highest temperature at which this occurs is interpreted as the beginning of the inhibition of recrystallization, or the static recrystallization critical temperature (SRCT). The time which corresponds to the beginning of each plateau depends on the temperature and the same can be said of the time which corresponds to the end. The 


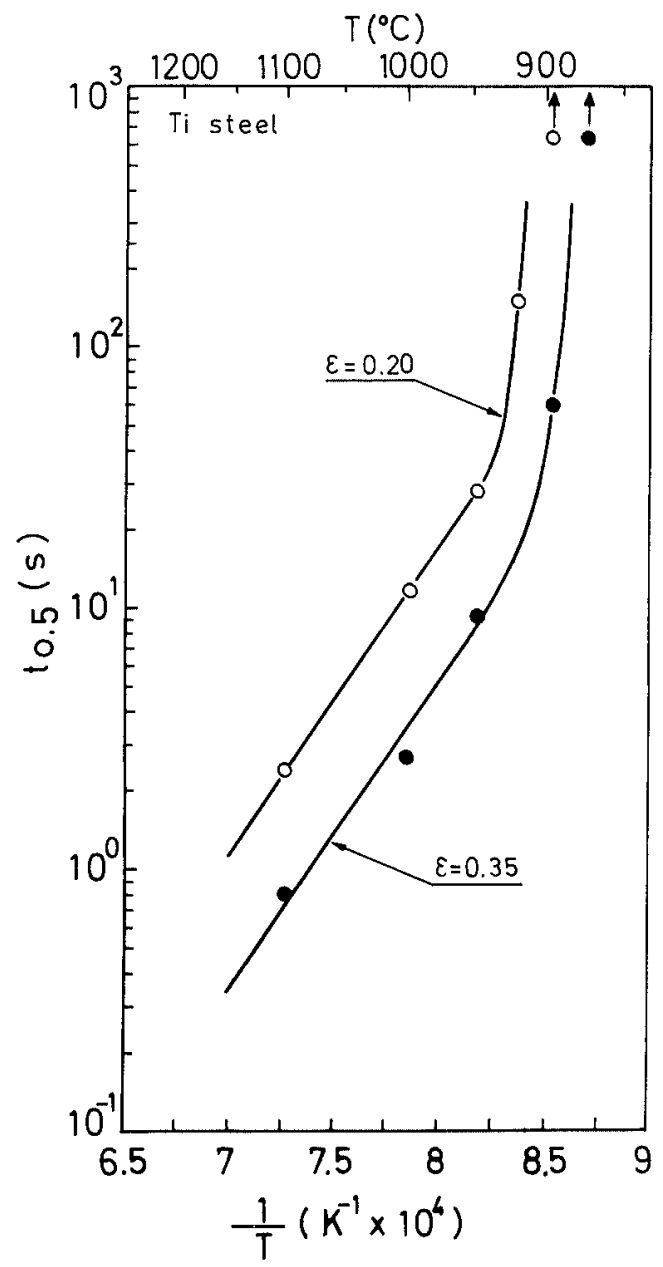

Fig. 10. Plot of $t_{0.5}$ against the reciprocal of the temperature for Ti steel.

section of the curve before the start of the plateau is similar to the curves in which the plateau did not appear and the same occurs in the later section of the curve, indicating therefore that the recrystallization kinetics before and after the plateau are similar to what occurs at higher temperatures, though obviously the kinetics are slower.

The activation energy was measured taking $\ln \left(t_{0.5}\right)$ as a function of $1 / T$, the slope being equal to $Q / R$. Figures $\mathbf{8}, 9$ and $\mathbf{1 0}$ show the graphs for steels with $\mathrm{Nb}, \mathrm{V}$ and $\mathrm{Ti}$, respectively, and the activation energy is constant to a certain temperature, below which it rises increasingly. The route of the curvilinear part of the graph has been made under the criteria of maintaining as far as possible a certain parallelism between the curves corresponding to both strains, something which has been verified by other esperimental results. ${ }^{1,29)}$ The activation energy was calculated for the interval of temperatures in which it is constant, and at other points of the curvilinear part. The $\ln Q$ was plotted $v s .1 / T$, giving the graphs in Figs. 11,12 and 13, which correspond to steels with $\mathrm{Nb}, \mathrm{V}$ and $\mathrm{Ti}$, respectively, and the recrystallization critical temperature will be given by the intersection of the horizontal line with the sloping line. The SRCT of each steel for the two strains is shown in Table 3 which also includes the deduced temperatures $\left(T_{s}\right)$ of the products of solubility for the two precipitates. ${ }^{30)}$ The comparison

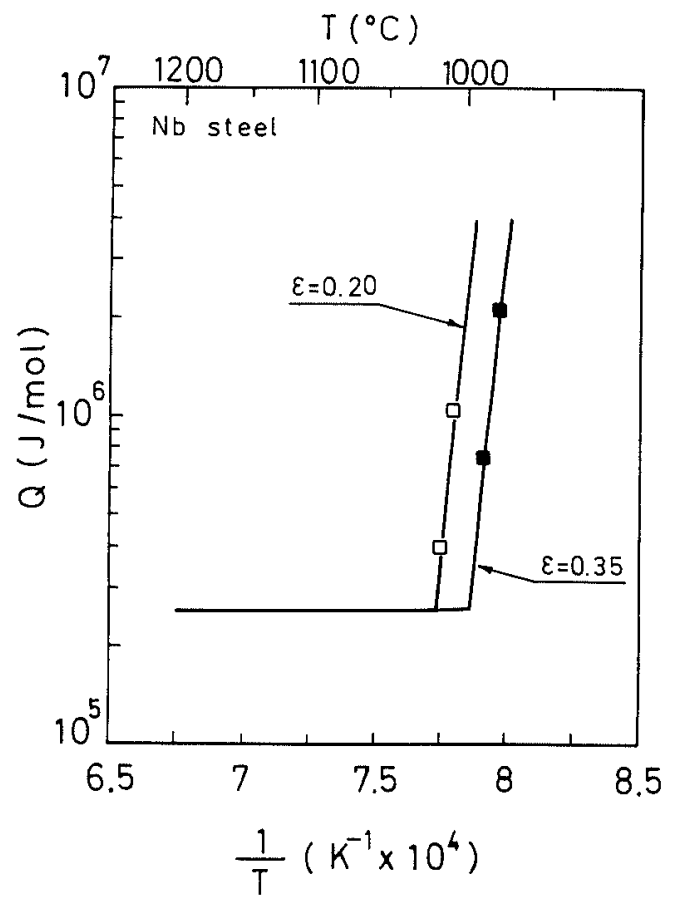

Fig. 11. Plot of the activation energy against the reciprocal of the temperature for $\mathrm{Nb}$ steel.

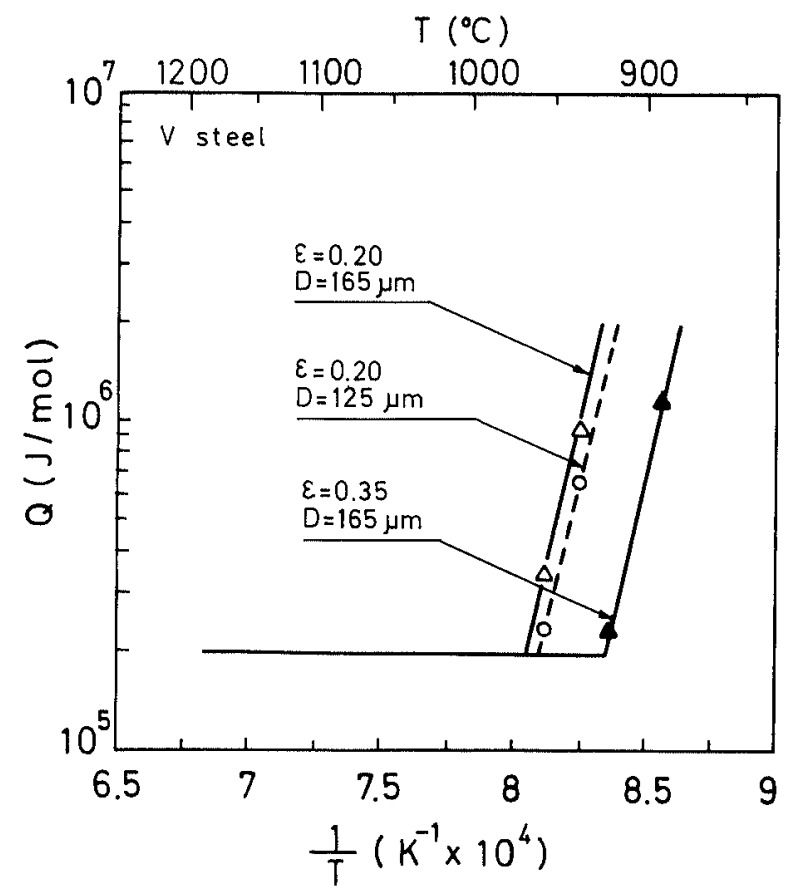

Fig. 12. Plot of the activation energy against the reciprocal of the temperature for $\mathrm{V}$ steel.

between SRCT and $T_{s}$ shows that the precipitates of $\mathrm{Nb}$ induced by the strain can be nitrides or carbides, though preferably the former, that the precipitates of $\mathrm{V}$ are nitrides and those of $\mathrm{Ti}$ are carbides. In this last case the existence should be pointed out of titanium nitrides at the heating temperature $\left(1230^{\circ} \mathrm{C} \times 10 \mathrm{~min}\right)$, easily observable with the replica microscope, but the induced precipitation, responsible for the presence of the plateau, is due to the carbides. As was to be expected, the highest SRCT correspond to the steel with $\mathrm{Nb}$ in spite of its lower microalloy. On the other hand, it is interesting to 


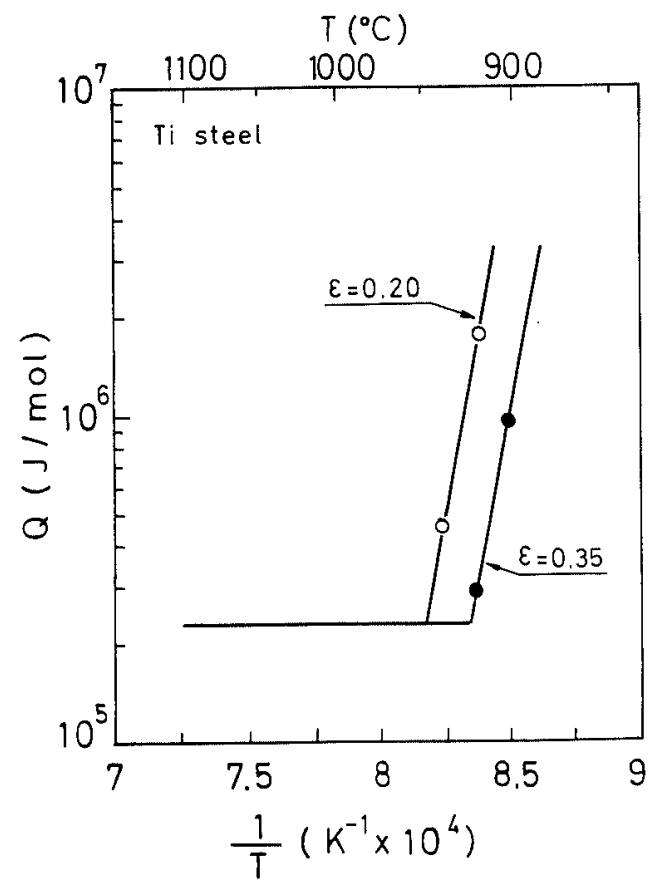

Fig. 13. Plot of the activation energy against the reciprocal of the temperature for Ti steel.

Table 3. 'Static recrystallization critical temperature (SRCT, ${ }^{\circ} \mathrm{C}$ ) determined experimentally and calculated solubility temperature. $\left(T_{s},{ }^{\circ} \mathrm{C}\right)$

\begin{tabular}{|c|c|c|c|}
\hline Steel & $\begin{array}{l}\operatorname{SRCT}\left({ }^{\circ} \mathrm{C}\right) \\
\varepsilon=0.20\end{array}$ & $\begin{array}{c}\mathrm{SRCT}\left({ }^{\circ} \mathrm{C}\right) \\
\varepsilon=0.35\end{array}$ & $T_{s}\left({ }^{\circ} \mathrm{C}\right) ;$ Eq. ${ }^{29)}$ \\
\hline $\mathrm{Nb}$ & 1021 & 1000 & $\begin{array}{l}1114 ; \log [\mathrm{Nb}][\mathrm{N}]=2.80-8500 / T \\
1095 ; \log [\mathrm{Nb}][\mathrm{C}]=3.42-7900 / T\end{array}$ \\
\hline $\mathrm{V}$ & $\begin{array}{l}969^{*} \\
961^{* *}\end{array}$ & $\begin{array}{l}925^{*} \\
-\end{array}$ & $\begin{aligned} 1067 ; \log [\mathrm{V}][\mathrm{N}] & =3.63-8700 / T \\
820 ; \log [\mathrm{V}][\mathrm{C}] & =6.72-9500 / T\end{aligned}$ \\
\hline $\mathrm{Ti}$ & 950 & 924 & $\begin{array}{l}1882 ; \log [\mathrm{Ti}][\mathrm{N}]=3.93-15188 / T \\
1163 ; \log [\mathrm{Ti}][\mathrm{C}]=5.33-10475 / T\end{array}$ \\
\hline
\end{tabular}

$*$ austenite grain size $=165 \mu \mathrm{m}$.

$* *$ austenite grain size $=125 \mu \mathrm{m}$.

observe that the SRCT steel is much lower than the corresponding $T_{s}$, to the order of $100^{\circ} \mathrm{C}$ for the steels with $\mathrm{Nb}$ and $\mathrm{V}$ and $200^{\circ} \mathrm{C}$ for the steel with $\mathrm{Ti}$. If the Ti previouly combined with the $\mathrm{N}(\mathrm{Ti}=0.035 \%$, wt $)$ is discounted, the corresponding $T_{s}$ for the titanium carbides would be of $1111^{\circ} \mathrm{C}$, and not $1163^{\circ} \mathrm{C}$ as is indicated in the Table 3, and the difference between $T_{s}$ and SRCT now would be of $160^{\circ} \mathrm{C}$ when the strain is 0.20 . Obviously SRCT should always be lower than $T_{s}$, though the strain is small, as induced precipitation does not occur in the thermodynamic equilibrium inherent in the products of solubility.

From the curves which present a plateau in Figs. 1 to 7 , it is possible to deduce the start times $\left(P_{s}\right)$ and finish times $\left(P_{f}\right)$ of the induced precipitation, which the authors indentify with the start and finish of the plateau for each temperature. This hypothesis may not be totally correct as it is possible that the induced precipitation may begin before the start of the plateau, but it is easily observable that before and after the plateau the curves show approximately the same slope as those where the plateau does not appear, and therefore the authors believe that

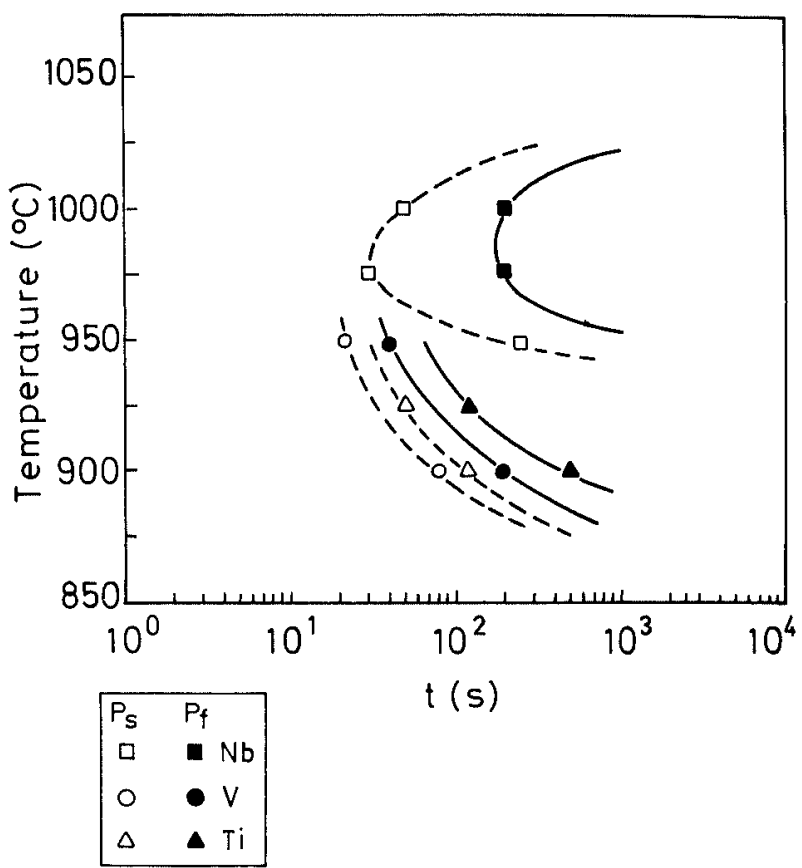

Fig. 14. PTT diagrams for $\mathrm{Nb}, \mathrm{V}$ and $\mathrm{Ti}$ steels. $\varepsilon=0.20$; $\dot{\varepsilon}=3.63 \mathrm{~s}^{-1}$.

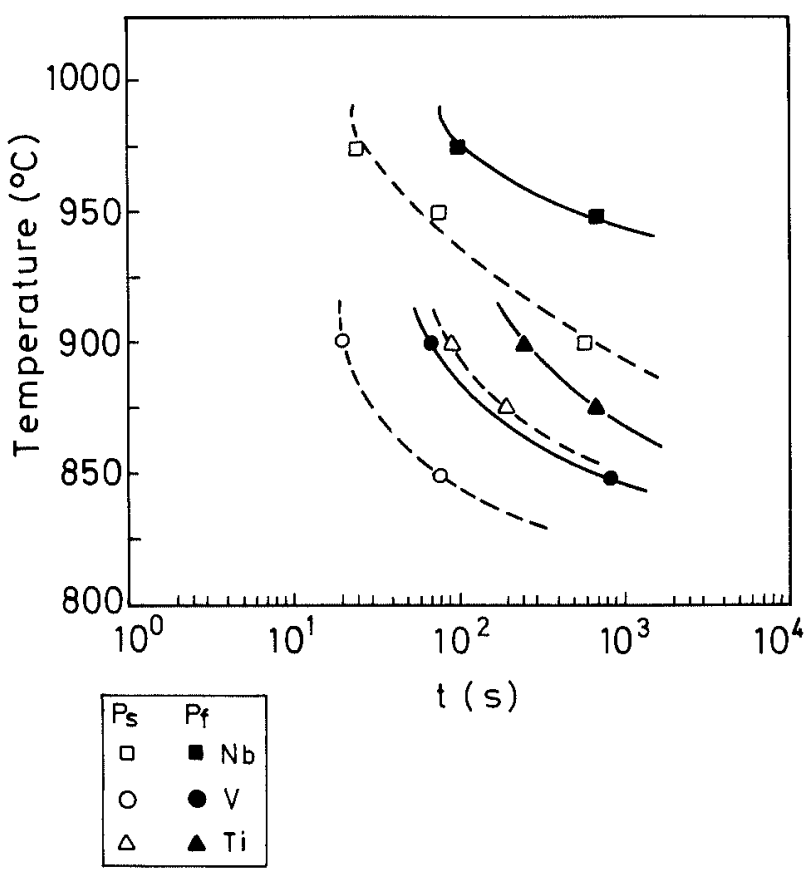

Fig. 15. PTT diagrams for $\mathrm{Nb}, \mathrm{V}$ and $\mathrm{Ti}$ steels. $\varepsilon=0.35$; $\dot{\varepsilon}=3.63 \mathrm{~s}^{-1}$.

the hypothesis established is approximately correct. On the other hand, in general the experimental points situated on the plateau give a lower recrystallized fraction when the time is longer, which indicates a progressive precipitation in the period of time which defines each plateau. In Figs. 14 and 15 the precipitation-timetemperature (PTT) diagrams have been represented for all the steels and the two strains respectively. It is observed that both the start times and the end times of the induced precipitation follow the law established by other authors ${ }^{19)}$ for microalloyed steels with $\mathrm{Nb}$, though to complete the nose of each curve it would have been 
necessary to determine the recrystallized fraction at other temperatures, obviously below SRCT. The PTT diagram obtained in this way shows that an increase in the strain advances precipitation and that all the $P_{s}$ and $P_{f}$ curves consist of periods of time with similar durations, which indicates that the nucleation of the different precipitates, as well as the precipitation kinetics, should be similar. However, if we compare the steels with $\mathrm{V}$ and $\mathrm{Ti}$, both with similar SRCT values, it can be observed that the vanadium nitrides begin to precipitate before the titanium carbides, especially when the strain increases. In the case of steel with $\mathrm{Nb}$, the results obtained have been sufficient to plot the nose of the PTT diagram when the strain is of 0.20 and it can be seen that the temperature corresponding to the shortest $P_{s}$ time, coinciding with the nose of the curve, is somewhat lower than SRCT, as was to be expected, and that as the temperature descends, the $P_{s}$ time increases significantly. This fact indicates the desirability in the hot rolling of microalloyed steels, such as for example in the hot strip mill, not only for it to be possible to obtain a strongly deformed austenite in the final passes, an indispensable requisite both for producing a small ferrite grain size ${ }^{3)}$ and for advancing precipitation, but also that the cooling rate following the rolling is not excessively fast, as this could lead to precipitation not being complete.

The regression calculations carried out with the results obtained allowed an Avrami equation to be constructed for each one of the steels. The exponents " $q$ " and " $r$ ", representing the strain rate and the grain size in Eq. (2) were given values of -0.44 and 1 , respectively, which are average values found in a high number of tests with different steels, both with $\mathrm{C}-\mathrm{Mn}$ steels and microalloyed steels. ${ }^{3)}$ A clear influence of the temperature on the exponent $n$ in Eq. (1) was found, however its influence on the strain is not clear, as its influence is positive in some cases, that is to say $n$ increases slightly with the strain, and at other times the reverse occurs, which would lead us to statistical evaluations, and the same it could be said of the strain rate and the grain size. The equations found for the three steels, as well as their application times are the following:

a) Nb steel:

$$
\operatorname{SRCT}_{\mathrm{Nb}}(\mathrm{K})=1326.5-178.3 \ln (1+\varepsilon)
$$

When $T>\mathrm{SRCT}_{\mathrm{Nb}}$ the following equations are applicable:

$$
\begin{aligned}
& t_{0.5}=3.943 \cdot 10^{-13} \varepsilon^{-1.96} \dot{\varepsilon}^{-0.44} D \exp \left(\frac{262000}{R T}\right) \\
& n=27.35 \exp \left(-\frac{40000}{R T}\right)
\end{aligned}
$$

When $T<\mathrm{SRCT}_{\mathrm{Nb}}$ the activation energy has the following expression:

$$
Q=9.815 \cdot 10^{-63} \varepsilon^{-4.1} D^{1.9} \exp \left(\frac{1500000}{R T}\right) \ldots \ldots
$$

b) V steel:

$$
\operatorname{SRCT}_{V}(K)=1310-373.6 \ln (1+\varepsilon)
$$

When $T>\mathrm{SRCT}_{\mathrm{V}}$ the following equations are applicable:

$$
\begin{array}{r}
t_{0.5}=3.103 \cdot 10^{-11} \varepsilon^{-1.92} \dot{\varepsilon}^{-0.44} D \exp \left(\frac{198000}{R T}\right) \\
n=4.33 \exp \left(-\frac{17000}{R T}\right) \ldots \ldots \ldots \ldots \ldots \ldots \ldots \ldots
\end{array}
$$

When $T<$ SRCT $_{\mathrm{V}}$ the activation energy has the following expression:

$$
Q=3.052 \cdot 10^{-32} \varepsilon^{-4.5} D^{1.9} \exp \left(\frac{700000}{R T}\right) \ldots \ldots . .(
$$

c) Ti steel:

$$
\operatorname{SRCT}_{\mathrm{Ti}}(\mathrm{K})=1263-220.7 \ln (1+\varepsilon)
$$

When $T>\mathrm{SRCT}_{\mathrm{Ti}}$ the following equations are applicable:

$$
\begin{array}{r}
t_{0.5}=3.702 \cdot 10^{-12} \varepsilon^{-2.15} \dot{\varepsilon}^{-0.44} D \exp \left(\frac{227000}{R T}\right) \ldots \ldots \\
n=4.81 \exp \left(-\frac{20000}{R T}\right) \ldots \ldots \ldots \ldots \ldots \ldots
\end{array}
$$

When $T<\mathrm{SRCT}_{\mathrm{Ti}}$ the activation energy has the following expression:

$$
Q=3.145 \cdot 10^{-35} \varepsilon^{-2.9} D^{1.9} \exp \left(\frac{800000}{R T}\right) \ldots \ldots
$$

In Eqs. (3), (7) and (11) the influence of the grain size on SRCT has not been taken into account due to the fact that the application of the previous equations give better results than if this influence had been considered. This is probably due to the fact that, on the one hand, it has been seen previously that the precipitation temperature and time do not depend on the grain size and, on the other hand, the influence of the grain size on the recrystallized fraction when the austenite is strongly strengthened, as occurs in the finishing mill, is much less significant.

In Eqs. (4), (8) and (12), the exponents of the strain vary very little from one steel to another and though it would have been possible to take value 2 for all of them, it has been preferred to leave the value that resulted from the regression calculations in each one. The activation energy of the steel with $\mathrm{Nb}$ is the highest of the three steels $(262000 \mathrm{~J} / \mathrm{mol})$ and this means that the $\mathrm{Nb}$ in solution significantly delays static recrystallization. The activation energy of the steel with $\mathrm{V}$ has been the lowest $(198000 \mathrm{~J} / \mathrm{mol}$ ) and its value is due to the presence of other elements in solution ( $\mathrm{C}, \mathrm{Mn}, \mathrm{Si})$, since it has recently been demonstrated that vanadium in solution, in microalloying quantities, does not influence the value of the activation energy. ${ }^{29)}$ With regard to the steel with Ti its activation energy was $227000 \mathrm{~J} / \mathrm{mol}$, it being known that the presence of titanium nitrides increase the activation energy. ${ }^{1)}$

When the temperature is lower than SRCT, the activation energy is a function of the temperature, and Eqs. (6), (10) and (14) are now those which are considered. What is derived from these functions of $1 / R T$ indicate that the steel with $\mathrm{Nb}$ gives the highest slope, 
$1500000 \mathrm{~J} / \mathrm{mol}$ compared with 700000 and $800000 \mathrm{~J} / \mathrm{mol}$ in the steels with $\mathrm{V}$ and Ti respectively, indicating in this way that the precipitates of $\mathrm{Nb}$ inhibit recrystallization more efficiently than the precipitates of $\mathrm{V}$ and $\mathrm{Ti}$. The exponent of the strain is now higher than in the preceding equations, reaching values close to 4 .

Finally all the previous equations, together with those already published ${ }^{3)}$ on compensated time, residual strain and the austenite grain size, make it possible to calculate the accumulated strain and the austenite grain size at the end of the hot rolling process or to optimize the preocess in accordance with the most suitable microstructure.

\section{Conclusions}

The results obtained allow us to draw the following conclusions:

(1) The methodology used to experimentally determine the SRCT in microalloyed steels simultaneously allows us to modelize Avrami's equation for the recrystallized fraction and to discover the kinetics of precipitation through the plotting of the PTT diagrams. Although the number of tests to be carried out is much greater than when other methods reported in the bibliography are used, the method explained here makes it possible to have a complementary knowledge of the kinetics of recrystallization and precipitation, both aspects being necessary for the optimization of microstructures in hot rolling.

(2) The SRCT of each steel depends not only on the content and type of microalloy but also on the strain and, to a lesser extract, on the grain size. The value of SRCT is much lower than the solubility temperature, a considerable subcooling being necessary $\left(\Delta T=T_{s}-\right.$ SRCT) in order to bring about induced precipitation. For the strains applied in the tests $(0.20 ; 0.35)$, the subcooling $\Delta T$ is approx. $100^{\circ} \mathrm{C}$ for the steels with $\mathrm{Nb}$ and $\mathrm{V}$ and up to $200^{\circ} \mathrm{C}$ for the steel with $\mathrm{Ti}$.

(3) Niobium in solution delays static recrystallization to a greater extent than the precipitates of titanium nitride.

(4) The precipitates of niobium are more effective to inhibit recrystallization than those of vanadium and titanium, due surely to their smaller size.

(5) The duration of the start and end times of the induced precipitation is similar in the three steels. The temperature which corresponds to the minimum start and end times of the precipitation (nose of the PTT curves) is higher in steel with $\mathrm{Nb}$ than in steels with $\mathrm{V}$ and $\mathrm{Ti}$.

(6) Equations (3) to (14), together with others already published ${ }^{3)}$ make it possible to accurately calculate the accumulated strain and the austenite grain size in the hot rolling of the steels studied. It should not be forgotten that the PTT curves are of great use in the rolling of microalloyed steels as a rapid cooling rate, accompanied by a small accumulated strain, can prevent precipitation from being complete.

\section{Acknowledgments}

The authors are grateful for the financial support of the DGICYT of Spain (Project PB89-0022). Mancilla's studies are sponsored by the CONACYT of Mexico

\section{REFERENCES}

1) S. F. Medina and P. Fabregue: J. Mater. Sci., 26 (1991), 5427.

2) P. Choquet, B. Lamberterie, C. Perdrix and H. Biausser: Proc of the 4th Int. Steel Rolling Conf., ed. by IRSID, Deauville, France, (1987), B5.1.

3) S. F. Medina and V. López: ISIJ Int., 33 (1993), 605.

4) C. M. Sellars: Mater. Sci. Technol., 6 (1990), 1072.

5) C. M. Sellars: Hot Working and Forming Processes, ed. by C. M. Sellars and G. J. Davies, Met. Soc., London, (1980), 67.

6) T. Siwecki: ISIJ Int., 32 (1992), 368

7) E. Anelli: ISIJ Int., 32 (1992), 440.

8) O. Kwon: ISIJ Int., 32 (1992), 350.

9) A. Laarasoui and J. J. Jonas: ISIJ Int., 31 (1991), 95.

10) A. Laarasoui and J. J. Jonas: Metall. Trans. A, 22A (1991), 151.

11) P. D. Hodgson and R. K. Gibbs: ISIJ Int., 32 (1992), 1329.

12) A. Le Bon, J. Rofes-Vernis and C. Rossard: Mém. Sci. Rev. Métall., 57 (1973), 577.

13) K. J. Irvine, T. Gladman, J. Orr and F. B. Pickering: J. Iron Steel Inst., 208 (1970), 717.

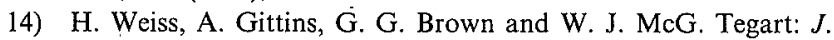
Iron Steel Inst., 211 (1973), 703.

15) A. Najafi-Zadeh, S. Yue and J. J. Jonas: ISIJ Int, 32 (1992), 213.

16) L. N. Pussegoda and J. J. Jonas: ISIJ Int., 31 (1991), 278.

17) F. H. Samuel, S. Yue, J. J. Jonas and B. A. Zbinden: ISIJ Int., 29 (1989), 878.

18) F. H. Samuel, S. Yue, J. J. Jonas and K. R. Barnes: ISIJ Int., 31 (1991), 278.

19) B. Dutta and C. M. Sellars: Mater. Sci. Technol., 3 (1987), 197.

20) K. C. Russel: Adv. Colloid Interface Sci., 13 (1980), 205.

21) B. Dogan, L. E. Collins and J. D. Boyd: Metall. Trans. A., 19A (1988), 1221.

22) L. N. Pussegoda, P. D. Hodgson and J. J. Jonas: Mater. Sci. Technol., 7 (1991), 129.

23) L. N. Pussegoda, S. Yue and J. J. Jonas: Metall. Trans. A., 21A (1990), 153.

24) L. J. Cudy: Int. Conf. of the Thermomechanical Processing of Microalloyed Austenite, Metall. Soc. of AIME, Pittsburgh, (1991), 129.

25) H. L. Andrade, M. G. Akben and J. J. Jonas: Metall. Trans. A., 14A (1983), 1967.

26) P. Choquet, A. Le Bon and C. Perdrix: Strength of Metals and Alloys, CISMA 7, Vol. 3, ed. by H. J. Mcqueen et al., Pergamon Press, Oxford, (1986), 1205.

27) S. F. Medina: Rev. Métal. Madrid, 23 (1987), 419

28) A. Faessel: Rev. Métal., Cah. Inf. Tech., 4 (1976), 875.

29) S. F. Medina, J. E. Mancilla and C. A. Hernández: J. Mater. Sci., 28 (1993), 5317.

30) K. Narita: Trans. Iron Steel Inst. Jpn., 15 (1975), 145. 